\title{
Road Traffic Noise at the Residence, Annoyance, and Cognitive Function in Elderly Women
}

\author{
Kateryna B. Fuks ${ }^{+} \mathbb{C}$, Claudia Wigmann ${ }^{+} \mathbb{C}$, Hicran Altug and Tamara Schikowski * \\ IUF-Leibniz Research Institute for Environmental Medicine, 40225 Düsseldorf, Germany; \\ kateryna.fuks@iuf-duesseldorf.de (K.B.F.); claudia.wigmann@iuf-duesseldorf.de (C.W.); \\ hicran.altug@iuf-duesseldorf.de (H.A.) \\ * Correspondence: tamara.schikowski@iuf-duesseldorf.de \\ t These authors contributed equally to this work.
}

Received: 15 March 2019; Accepted: 18 May 2019; Published: 20 May 2019

\begin{abstract}
The detrimental effects of traffic noise on cognition in children are well documented. Not much is known about the health effects in adults. We investigated the association of residential exposure to road traffic noise and annoyance due to road traffic noise with cognitive function in a cohort of 288 elderly women from the longitudinal Study on the influence of Air pollution on Lung function, Inflammation and Aging (SALIA) in Germany. Residential noise levels-weighted 24-h mean $\left(\mathrm{L}_{\mathrm{DEN}}\right)$ and nighttime noise $\left(\mathrm{L}_{\mathrm{NIGHT}}\right)$ - were modeled for the most exposed facade of dwellings and dichotomized at $\geq 50 \mathrm{~dB}(\mathrm{~A})$. Traffic noise annoyance (day and night) was estimated by questionnaire. Cognitive function was assessed using the Consortium to Establish a Registry on Alzheimer's Disease (CERAD-Plus) Neuropsychological Assessment Battery. The modeled noise levels were associated with impaired total cognition and the constructional praxis domain, independently of air pollution. Self-reported noise annoyance was associated with better performance in semantic memory and constructional praxis domains. This finding should be interpreted with caution since we could not control for potential confounding by hearing loss. Noise levels and annoyance were associated, but their health effects seemed mutually independent.
\end{abstract}

Keywords: road traffic noise; noise annoyance; cognitive impairment

\section{Introduction}

Adverse health effects of ambient noise exposure are divided into auditory and non-auditory [1]. There is only one auditory effect-hearing loss. The non-auditory effects, suggested by epidemiologic and mechanistic studies, include cardiovascular diseases, annoyance, and sleep disturbance [1]. Noise has been shown to adversely affect cognitive function in children, causing communication difficulties, impaired attention, increased arousal, learned helplessness, frustration, annoyance, and sleep disturbance [1,2].

Not much is known about the effects of noise on cognition in adults. Elmenhorst and colleagues investigated the short-term effects of nocturnal air traffic noise on cognitive function in healthy volunteers [3]. The authors found that nighttime traffic noise exposure was associated with impaired reaction times [3,4]. Similarly, in a panel study on nighttime aircraft noise exposure, Schapkin and colleagues observed a selective impairment of the inhibitory functioning and worsening in sleep quality in some participants [5]. However, the results were mixed: the authors observed no decrement in performance after exposure, possibly due to a compensatory effect [5]. In another panel study, noise exposure was associated with slower psychomotor speed, reduced episodic and working memory, and more cautious decision making; factors like cognition, noise sensitivity, and sleep quality influenced these associations [6]. 
The long-term effects of residential noise exposure on cognition have been scarcely investigated so far, despite the dominance of this exposure in many populations. For example, about 125 million residents of the European Union are exposed to 24-h noise levels greater than 55 decibels [7]. It is plausible that acute impairments due to noise exposure could potentiate a chronic deterioration in cognitive function.

Only one study so far has investigated the chronic effect of road traffic noise on cognition [8]. Tzivian and colleagues studied the effects of traffic-related exposure to noise and air pollution on mild cognitive impairment (MCI) [8]. MCI is defined as a "cognitive decline greater than expected for an individual's age and educational level, but that does not interfere notably with activities of daily life" and is a major risk factor for progression to Alzheimer's disease ([9], p. 1262). Using data from a large population-based study, Tzivian and colleagues found positive associations of road traffic noise as well as exposure to fine particulate matter and soot with overall and amnestic, but not with non-amnestic, MCI [8]. The associations with road traffic noise were robust to adjustment for air pollution, but not vice versa [8].

In contrast to other environmental risks, such as air pollution or ionizing radiation, noise can be perceived by an affected person and cause annoyance, defined as "a feeling of resentment, displeasure, discomfort, dissatisfaction, or offense when noise interferes with someone's thoughts, feelings, or actual activities" ([10], p. 126). Annoyance can lead to disturbed activities, somatic and psychosomatic health effects [10]. It is not clear yet whether annoyance can contribute to the effects of noise on cognitive function.

In this study, we aimed to broaden the evidence on the long-term effects of noise on cognition, using a cohort of elderly women from an industrialized area in Western Germany, including both modeled noise levels at the residence and self-estimated noise annoyance.

\section{Materials and Methods}

\subsection{Study Population}

We used data from the Study on the influence of Air pollution on Lung function, Inflammation and Ageing (SALIA), an ongoing cohort study in the state of North Rhine-Westphalia in Germany. The design of the SALIA study has been described elsewhere [11-13]. Briefly, 4874 women aged 55 years took part in the baseline examination in 1985-1994. The study participants resided in five cities of the highly industrialized Ruhr area and in two counties in rural Münsterland with very low pollution levels, serving as a reference. The baseline response rate was $70 \%$ and was stable over time with no systematic differences between study areas [11]. In 2006-2007, a questionnaire on health status was sent to 4027 participants who were still alive and residing in the study area; 2116 responded (53\%) and were invited to the clinical examination. In 2007-2010, all women who agreed to participate and whose lung function had been measured at baseline took part in a comprehensive clinical follow-up examination, comprising paper-assisted interview, cognitive assessment, lung function measurement, and blood test. The follow-up sample comprised 834 women (39\% of the questionnaire follow-up sample and $17 \%$ of the baseline sample) aged 67 to 80 years. All participants gave written informed consent. The Medical Ethics Committee of the University of Bochum approved the follow-up examination (approval number 2732).

\subsection{Residential Noise Exposure}

We assessed modeled ambient road traffic noise as a measure of objective noise exposure for the year 2006 preceding the follow-up examination. Noise levels were modeled according to the EU Directive 2002/49/EC for the most exposed facade of dwellings [14]. Noise levels were modeled as weighted 24-h mean $\left(\mathrm{L}_{\mathrm{DEN}}\right)$ and night-time mean $\left(\mathrm{L}_{\mathrm{NIGHT}}\right)$. The modelled noise ranges were between 30.5-73.8 dB(A) and 21.7-63.5 dB(A) for 24-h mean and night-time mean road traffic noise levels, 
respectively. For the analyses, noise variables were dichotomized at $\geq 50 \mathrm{~dB}(\mathrm{~A})$. Noise data were available only in a subset of participants, all residing in the Ruhr area $(N=319$; Figure 1$)$.

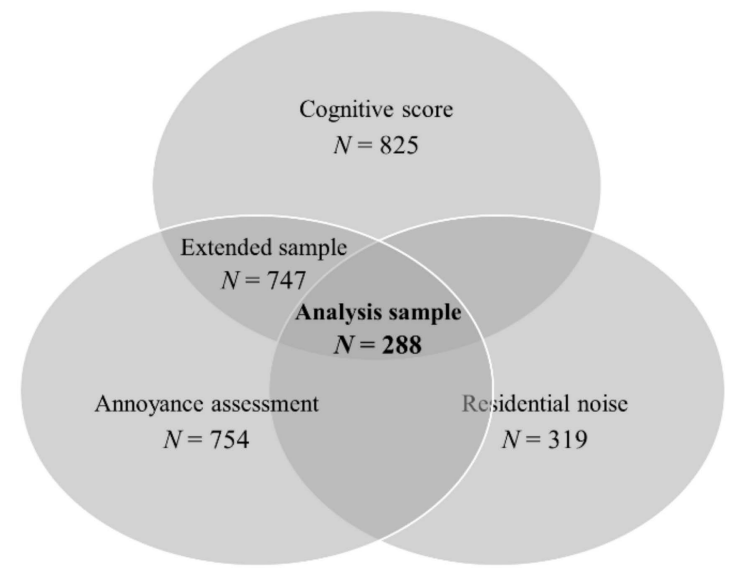

Figure 1. Numbers of participants with non-missing cognitive function and noise data.

\subsection{Noise Annoyance}

Annoyance due to traffic noise ("noise annoyance") was estimated by a 5-point scale recommended by the ICBEN (International Commission on Biological Effects of Noise) [15]. The study participants were asked: "How much do you generally feel disturbed or annoyed by traffic noise when being at home?". Day- and night-time annoyances were assessed separately. The answers were assessed with a Likert scale as "not at all", "somewhat", "moderately", "strongly", and "very strongly". We considered annoyance present for answers "somewhat", "moderately", "strongly", and "very strongly". The information on traffic noise annoyance was available for 754 participants (Figure 1).

\subsection{Assessment of Cognitive Function}

The assessment of cognitive function in the SALIA study has already been described [12,16]. Cognitive function was assessed using the Consortium to Establish a Registry on Alzheimer's Disease (CERAD) Neuropsychological Assessment Battery. The German version of it, CERAD-Plus, was applied (Memory Clinic 2009). The cognitive tests were administered by trained personnel and double checked by a clinically trained psychologist. CERAD-Plus consists of 18 test items belonging to four cognitive domains and Mini-Mental State Examination (MMSE). All items were standardized for age and educational level as z-scores using reference values from a German-speaking population. A z-score of 0 and higher indicates cognitive performance equal to or higher than the one expected for the participant's age and educational level, while a score $<0$ indicates impaired cognition. Similarly to a previous study on the adverse effects of air pollution on cognitive scores in the SALIA cohort [12], we selected 10 items which assess tasks directly performed by the participant as well as MMSE and the total CERAD score (sum of all $18 \mathrm{z}$-scores) to assess the global cognition (Table 1 ). All z-scores were dichotomized as $<0$ and $\geq 0$ (reference) for the analyses. Scores for at least one CERAD-Plus item were available for 825 participants (Figure 1). 
Table 1. The composition of the Consortium to Establish a Registry on Alzheimer's Disease (CERAD)-Plus score.

\begin{tabular}{ll}
\hline \multicolumn{1}{c}{ Cognitive Domain } & Subtests/Scores \\
\hline Semantic memory & $\begin{array}{l}\text { Semantic fluency test (SeFl), Phonetic fluency test/S words (PhFl), } \\
\text { Boston naming test (BNT) }\end{array}$ \\
\hline Episodic memory & $\begin{array}{l}\text { Word list learning test (WL-L; sum of word list learning (1) }{ }^{1} \text { word } \\
\text { list learning, (2) word list learning, (3) word list recall test (WL-R), } \\
\text { word list intrusions, word list savings, word list recognition }\end{array}$ \\
\hline Constructional praxis & Figure copying (Fig-C), figure recall (Fig-R), figure savings \\
\hline Executive function & Trail making test (TMT-A, TMT-B, ratio TMT-B/A) \\
\hline Mini-Mental State Examination (MMSE) & \\
\hline Total score & \\
\hline $\begin{array}{l}1 \\
\text { The scores highlighted in grey are only included in the total CERAD-Plus score and have not been analyzed } \\
\text { the participant. }\end{array}$
\end{tabular}

\subsection{Covariates}

Information on smoking status and exposure to passive smoke was assessed via interview. Similar to the previous analyses with the CERAD-Plus score in SALIA [12], we additionally adjusted for socio-economic levels, assessed as the highest educational level of the participant or her spouse: low ( $<10$ years), medium (10 years), and high ( $>10$ years). As cognitive performance has been strongly linked to depression [17], we assessed diagnosed depression via self-report. As previous analyses with the SALIA study have shown an association of air pollution exposure with lower cognitive function [12,16], we included air pollution as a covariate in our analyses. Air pollution was assessed using the ESCAPE LUR model approach [18] as a yearly mean concentration of particulate matter with an aerodynamic diameter of $\leq 10 \mu \mathrm{m}\left(\mathrm{PM}_{10}\right)$ and nitrogen dioxide $\left(\mathrm{NO}_{2}\right)$ at the residence.

\subsection{Statistical Analyses}

We used logistic regression to analyze the associations of residential noise exposure and annoyance due to road traffic noise with cognitive function (analysis sample $N=288$, Figure 1). In the main model, we a priori adjusted for age (linear, squared, and cubic terms), smoking, passive smoking, and educational level. In an additional step, we adjusted for (1) annoyance in models with noise and noise in models with annoyance; (2) air pollutants $\mathrm{PM}_{10}$ and $\mathrm{NO}_{2}$; and (3) depression. Other sensitivity analyses included (1) employing the main model in the extended sample with non-missing subjective noise ( $N=747)$, and (2) using different cutpoints for dichotomizing the annoyance ("moderately" instead of "somewhat") and traffic noise levels ( $\geq 40 \mathrm{~dB}$ for $\mathrm{L}_{\text {NIGHT }}$ ). In addition, we performed an interaction analysis by combining objective and subjective noise levels in one exposure variable with levels "low/low", "high/low", "low/high", and "high/high". Analyses were performed with R version 3.5.0 [19].

\section{Results}

The analysis sample contained 288 participants with non-missing information on residential noise exposure, annoyance, and cognitive score (Figure 1 and Table 2). The mean age was about 75 years, almost half $(46.9 \%)$ of the participants or their spouses had a medium educational status (Table 2). Almost none of the participants smoked (3.8\% current smokers), while about two-thirds reported exposure to passive smoking at home (60.8\%). Regarding depression, $11.8 \%$ of the participants reported physician-diagnosed depression. We observed no substantial differences between the analysis sample and the extended study sample (Supplementary Materials, Table S1). 
Table 2. Individual and residential characteristics of the analysis sample.

\begin{tabular}{|c|c|c|c|}
\hline Variable & & Statistics & $N$ \\
\hline \multicolumn{4}{|l|}{ Individual characteristics } \\
\hline \multicolumn{2}{|l|}{ Age (years), mean $\pm S D$} & $74.5 \pm 2.2$ & 288 \\
\hline \multirow{4}{*}{ Educational status, $\%{ }^{1}$} & Low & $16.70 \%$ & 48 \\
\hline & Middle & $46.90 \%$ & 135 \\
\hline & High & $36.10 \%$ & 104 \\
\hline & Missing & $0.30 \%$ & 1 \\
\hline \multirow{3}{*}{ Smoking, \% } & Yes & $3.80 \%$ & 11 \\
\hline & No & $96.20 \%$ & 277 \\
\hline & Missing & $0 \%$ & 0 \\
\hline \multirow{3}{*}{ Passive smoking at home, $\%$} & Yes & $60.80 \%$ & 175 \\
\hline & No & $38.50 \%$ & 111 \\
\hline & Missing & $0.70 \%$ & 2 \\
\hline \multirow{3}{*}{ Physician-diagnosed depression } & Yes & $11.80 \%$ & 34 \\
\hline & No & $87.80 \%$ & 253 \\
\hline & Missing & $0.30 \%$ & 1 \\
\hline \multicolumn{4}{|l|}{ Residential characteristics } \\
\hline \multicolumn{4}{|l|}{ Residential noise } \\
\hline $\mathrm{L}_{\mathrm{DEN}}(\mathrm{dB}(\mathrm{A}))$, mean $\pm \mathrm{SD}$ & & $55.9 \pm 7.7$ & 288 \\
\hline $\mathrm{L}_{\mathrm{DEN}} \geq 50 \mathrm{~dB}(\mathrm{~A}), \%$ & & $74.70 \%$ & 215 \\
\hline $\mathrm{L}_{\mathrm{NIGHT}}(\mathrm{dB}(\mathrm{A}))$, mean $\pm \mathrm{SD}$ & & $47.2 \pm 7.4$ & 288 \\
\hline $\mathrm{L}_{\mathrm{NIGHT}} \geq 50 \mathrm{~dB}(\mathrm{~A}), \%$ & & $35.40 \%$ & 102 \\
\hline \multicolumn{4}{|l|}{ Traffic noise annoyance } \\
\hline \multirow{6}{*}{ Daytime, \% } & Not at all & $55.90 \%$ & 161 \\
\hline & Somewhat & $18.80 \%$ & 54 \\
\hline & Moderate & $14.60 \%$ & 42 \\
\hline & Strong & $7.60 \%$ & 22 \\
\hline & Very strong & $3.10 \%$ & 9 \\
\hline & Missing & $0 \%$ & 0 \\
\hline \multirow{6}{*}{ Night, $\%$} & Not at all & $76.70 \%$ & 221 \\
\hline & Somewhat & $11.10 \%$ & 32 \\
\hline & Moderate & $6.20 \%$ & 18 \\
\hline & Strong & $3.10 \%$ & 9 \\
\hline & Very strong & $2.80 \%$ & 8 \\
\hline & Missing & $0 \%$ & 0 \\
\hline \multicolumn{4}{|l|}{ Air pollution } \\
\hline $\mathrm{PM}_{10}\left(\mu \mathrm{g} / \mathrm{m}^{3}\right)$, mean $\pm \mathrm{SD}$ & & $28.0 \pm 2.3$ & 288 \\
\hline $\mathrm{NO}_{2}\left(\mu \mathrm{g} / \mathrm{m}^{3}\right)$, mean $\pm \mathrm{SD}$ & & $32.2 \pm 7.4$ & 288 \\
\hline
\end{tabular}

Mean levels of $\mathrm{PM}_{10}$ and $\mathrm{NO}_{2}$ at the residence were 28.0 and $32.2 \mu \mathrm{g} / \mathrm{m}^{3}$, respectively. Mean residential noise levels were $47.2 \mathrm{~dB}(\mathrm{~A}) \mathrm{L}_{\mathrm{NIGHT}}$ and $55.9 \mathrm{~dB}(\mathrm{~A}) \mathrm{L}_{\mathrm{DEN}}$, with $74.7 \%$ and $35.4 \%$ of participants being exposed to noise above the selected cutpoint (Table 2), respectively. Fifty-six percent of participants reported no annoyance by traffic noise in the daytime, and $76.7 \%$ reported no annoyance by traffic noise at night.

$\mathrm{L}_{\text {DEN }}$ and L LIGHT were strongly correlated, with a Spearman's rho of 0.99 (see Table 3), which is expected, since the definition of $\mathrm{L}_{\mathrm{DEN}}$ embraces $\mathrm{L}_{\mathrm{NIGHT}}$. Annoyance in the daytime and at night correlated moderately (0.63). We found weak correlations of noise annoyance with residential noise $(0.24-0.35)$. While annoyance and residential noise were both weakly correlated with $\mathrm{NO}_{2}$ concentrations, the correlation of $\mathrm{PM}_{10}$ concentrations was stronger with residential noise levels than with noise annoyance (Table 3 ). 
Table 3. Spearman correlations of the residential characteristics in the analysis sample $(N=288)$.

\begin{tabular}{lccccc}
\hline \multicolumn{1}{c}{ Parameter } & Annoyance Night & L DEN & L $_{\text {NIGHT }}$ & NO $_{\mathbf{2}}$ & PM $_{\mathbf{1 0}}$ \\
\hline Annoyance day & 0.63 & 0.35 & 0.34 & 0.32 & 0.16 \\
Annoyance night & 1 & 0.24 & 0.24 & 0.28 & 0.17 \\
$\mathrm{~L}_{\text {DEN }}$ & & 1 & 0.99 & 0.34 & 0.41 \\
$\mathrm{~L}_{\mathrm{NIGHT}}$ & & & 1 & 0.32 & 0.40 \\
$\mathrm{NO}_{2}$ & & & & 1 & 0.49 \\
$\mathrm{PM}_{10}$ & & & & & 1 \\
\hline
\end{tabular}

The average CERAD-Plus total score was below zero, with a mean value of -2.19 and a standard deviation of 10.10 , and less than half of the study sample $(44.9 \%$ ) had a total score of $\geq 0$ (Table 4 ). The distribution of the total score was left-skewed (Supplementary Materials, Figure S1). As for the individual tests, the average values were below 0 for 7 out of 11 tests, with $21.5 \%$ to $76.9 \%$ of participants having a score of $\geq 0$ (Table 4 ).

Table 4. Description of the CERAD-Plus scores in the study sample.

\begin{tabular}{lcccc}
\hline \multicolumn{1}{c}{ Test } & Subtest & Mean & Standard Deviation & Score $\geq \mathbf{0 ~ ( \% )}$ \\
\hline \multirow{3}{*}{ Semantic memory } & SeFl & -0.09 & 0.91 & $46.9 \%(N=288)$ \\
& BNT & 0.76 & 1.07 & $76.9 \%(N=286)$ \\
& PhFl & 0.63 & 1.13 & $69.7 \%(N=284)$ \\
\hline \multirow{2}{*}{ Episodic memory } & WL-L & -0.74 & 1.19 & $26.6 \%(N=282)$ \\
& WL-R & -0.19 & 1.14 & $37.7 \%(N=281)$ \\
\hline \multirow{2}{*}{ Constructional praxis } & Fig-C & -0.76 & 1.37 & $21.5 \%(N=284)$ \\
& Fig-R & -0.53 & 1.11 & $28.1 \%(N=281)$ \\
\hline \multirow{2}{*}{ Executive function } & TMT-A & -0.11 & 1.00 & $42.3 \%(N=284)$ \\
& TMT-B & 0.39 & 1.02 & $62.0 \%(N=284)$ \\
\hline \multirow{2}{*}{ MMSE } & TMT-B/A & 0.55 & 0.95 & $73.5 \%(N=283)$ \\
\hline Total score & & -0.82 & 1.25 & $27.1 \%(N=288)$ \\
\hline
\end{tabular}

\subsection{Residential Noise Levels and Cognitive Function}

We observed no associations of $\mathrm{L}_{\mathrm{NIGHT}} \geq 50 \mathrm{~dB}(\mathrm{~A})$ with cognitive scores in the main model (Figure 2 and Supplementary Materials, Table S2). However, using a lower cutpoint of $\geq 40 \mathrm{~dB}(\mathrm{~A})$ yielded associations with an impaired score of the figure copying test, similar to the one observed with $\mathrm{L}_{\text {DEN }}$ (Supplementary Materials, Table S3). Adjusting for annoyance and air pollutants $\mathrm{PM}_{10}$ and $\mathrm{NO}_{2}$ revealed a borderline significant association $(p<0.1)$ of $\mathrm{L}_{\mathrm{NIGHT}} \geq 50 \mathrm{~dB}(\mathrm{~A})$ with a better score on one of the trail making tests (Supplementary Materials, Table S2). 


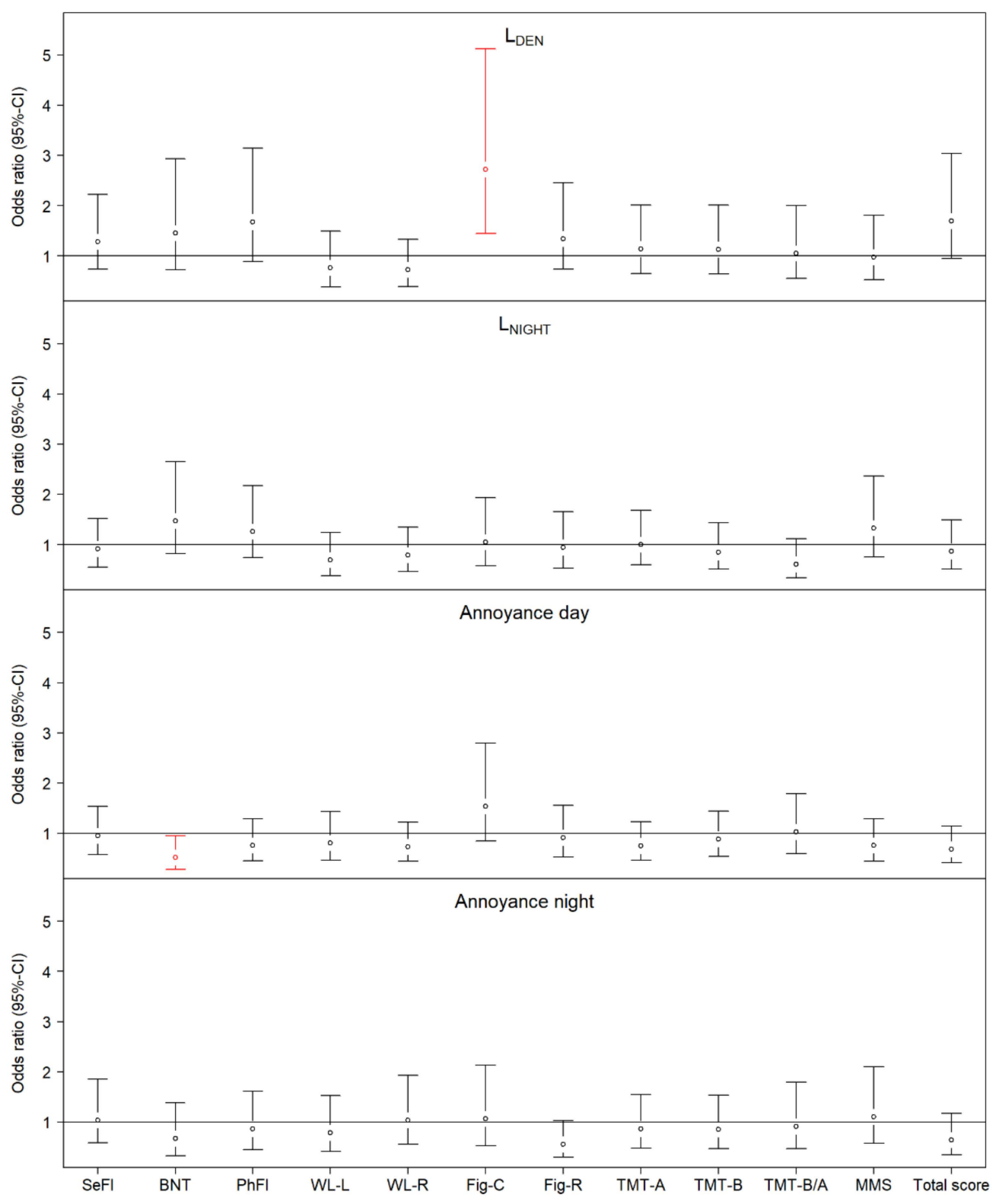

Figure 2. Association of residential noise and noise annoyance with dichotomized cognitive scores. Adjusted for age (linear, squared, and cubic terms), smoking, passive smoking, and educational level. We modeled the probability that score $<0$ (cognitive performance lower than expected for the participant's age and educational level). Statistically significant associations $(p<0.05)$ are marked red.

\subsection{Annoyance and Cognitive Function}

As shown in Figure 2, annoyance at daytime was associated with a better performance on the Boston naming test from the semantic memory domain (Odds ratio (OR) 0.52; 95\% CI: 0.28 to 0.95 ). Adjustment for residential noise levels and air pollutants, as well as analyses with the extended sample $(N=747)$, did not affect this association, but also revealed a borderline significant association with a better total score (Supplementary Materials, Tables S2 and S4). Moreover, in the extended sample, we observed a significant association with a better performance of word list learning from the episodic memory domain (Supplementary Materials, Table S4).

Annoyance at night showed a borderline significant relationship with better figure recall (constructional praxis): OR 0.56 (95\% CI: 0.30 to 1.03). This estimate became statistically significant when adjusted for physician-diagnosed depression (Supplementary Materials, Table S2). In the 
model adjusted for air pollutants, we found a borderline significant $(p<0.1)$ association of nighttime annoyance by traffic noise with a better total CERAD-Plus score (Supplementary Materials, Table S2). When performing analyses with the extended dataset, we found no associations of nighttime annoyance with better cognitive function (Supplementary Materials, Table S4). Moreover, nighttime annoyance was linked to impaired semantic fluency test at $p<0.1$ (Supplementary Materials, Table S4).

The findings with annoyance at day and night did not persist when using the alternative cutpoint "moderately" for the dichotomized annoyance definition (Supplementary Materials, Table S5).

\subsection{Combined Exposure to Noise and Annoyance with the Cognitive Function}

When compared to participants who were not exposed to $\mathrm{L}_{\mathrm{DEN}} \geq 50 \mathrm{~dB}(\mathrm{~A})$ and who also did not report annoyance by noise in the daytime (reference level), those who were exposed to high noise levels performed worse on figure copying, regardless of whether they reported annoyance or not (Supplementary Materials, Table S5). Participants with low noise exposure during nighttime but reporting annoyance showed better cognitive function according to the total CERAD score (Supplementary Materials, Table S6).

\subsection{Association of Noise with Annoyance}

A logistic regression of objective noise levels on subjective noise annoyance revealed significant positive associations in the crude as well as in the main adjusted model (Supplementary Materials, Table S7). Residing at $\mathrm{L}_{\mathrm{DEN}}$ levels of $\geq 50 \mathrm{~dB}(\mathrm{~A})$ was associated with $\mathrm{OR}$ for annoyance at day of 2.38 (95\% CI: 1.33 to 4.26 ); at $\mathrm{L}_{\mathrm{NIGHT}}$ levels of $\geq 50 \mathrm{~dB}(\mathrm{~A})$, the probability of nighttime annoyance was even higher (OR 3.21; 95\% CI: 1.79 to 5.76).

\section{Discussion}

We found complex relationships of noise exposure and noise annoyance with the cognitive performance of elderly women. While the ambient noise levels at the residence were associated with impaired cognitive performance in the constructional praxis domain (figure copying test) and with the total CERAD-Plus score, noise annoyance exhibited inverse associations with the domains of semantic memory (Boston naming test) and constructional praxis (figure recall). This is, to our knowledge, the first study on the long-term association of road traffic noise with cognition in the elderly that assessed noise annoyance in addition to ambient noise levels. However, this is an exploratory study and, due to the absent information on hearing loss, the results with annoyance might be biased. One should be cautious not to over-interpret the study findings.

The findings with residential noise levels were very similar to our earlier analysis of the SALIA cohort in which the effects of air pollution were investigated [12]. Previously, we reported a positive association of the long-term concentrations of particulate matter and nitrogen oxides at the residence with the impaired constructional praxis domain [12]. Similarities in the effects on cognition by noise and air pollution have been reported in another cohort study as well; the results with noise were more robust to adjustment for air pollution than the results with air pollution to adjustment with noise [8]. Our results with noise were independent of air pollution, as shown in the sensitivity analyses.

Constructional praxis tests are indicators of visual-spatial deficits [12]. Poor scores in figure copying tasks have been observed in patients with Alzheimer's disease (AD) or vascular dementia [20]. Constructional praxis copy scores allow for differentiating the advanced stages of AD or to discriminate between $\mathrm{AD}$ and depression; they were also useful in identifying brain pathology or the relationship between nutrition and cognitive function [21].

We found a somewhat counterintuitive positive correlation of annoyance and cognition: better scores in the semantic memory domain (Boston naming test) and in the constructional praxis domain (figure recall) were associated with higher annoyance of traffic noise in the daytime. In children, noise annoyance is correlated with lower cognition [22]. In older adults, annoyance might indicate a better hearing ability and thus better cognition; however, there are currently no studies available to 
confirm or refute this relationship. It is not likely that poor cognition drives poor perception directly, but rather that the relationship is quite complex, and one of the reasons for a worse cognition is a compensation to impaired perception [23]. In a panel study on noise, annoyance, and cognitive performance by Sandrock and colleagues, noisy conditions did not affect cognitive performance and mental strain in general, but a subgroup of participants with high noise sensitivity was more annoyed and performed worse [24]. We consider it possible that the results with annoyance were affected by an uncontrolled confounding factor due to the missing information on hearing loss. Hearing loss can affect both annoyance and cognition, fulfilling the definition of a confounder. Not adjusting for it might have introduced a spurious association between annoyance and cognition. Such confounding would likely drive the association away from null in a positive direction: if hearing loss is related to lower annoyance and lower cognition, than not adjusting for it would result in a spurious association of higher annoyance with higher cognition. Since we cannot control for hearing loss, the results with annoyance and cognition should be interpreted with caution.

As for the analyses with traffic noise, hearing loss is unlikely a confounder. It cannot affect the exposure and is highly unlikely a consequence of traffic noise exposure, considering the relatively low residential noise levels in the study population.

We found a positive association of noise with annoyance, independent of potential confounders. This is in line with a known monotonic relationship of noise levels with annoyance [4]. However, the associations of noise and annoyance with cognitive scores were mutually independent. This observation is plausible. Although annoyance is a consequence of noise exposure, there are a number of factors that influence noise-related annoyance and could therefore contribute to the associations with cognition. Personal characteristics-for example, anxiety, fear of noise source, and feeling that exposure could be avoided-were shown to modify the relationship between noise exposure and annoyance [10]. Residential factors, such as type of housing, location of rooms, noise barriers, window opening habits, etc., could also influence the degree of annoyance in relation to noise [25]. Incorporating these factors in further studies could explain the complex relationships between noise exposure, annoyance, and cognitive function in the elderly.

One of the theories aiming to explain noise effects on cognition is based on resource allocation theory [26]. Subjects, who were continuously exposed to noise (traffic police officers), demonstrated better discrimination and selection ability in the absence of noise, compared to the control subjects. This observation, according to Chiovenda and colleagues, reflects "their continuous need for diverting themselves from the environmental noise" ([26], p. 235). In the presence of noise, the difference in performance disappeared [26]. Noise-exposed subjects demonstrated higher susceptibility to background noise, reflected in a stronger regression of cognitive performance in the presence of background noise, than the controls [26]. In accordance with the resource allocation theory, the working memory network was modulated by exposure to background acoustic noise (reviewed in [27]). Noise can affect cognitive function through altered hippocampal signaling, as suggested by animal studies (reviewed in [8]). In an animal study, day- and nighttime traffic noise exposure caused the hypothalamic-pituitary-adrenal (HPA) axis hyperactivity, anxiety behavior, worse learning, memory, and coordination; it also affected the brain measures [28]. Noise-triggered activation of the HPA axis, measured as the concentration of its product cortisol, was observed in a panel study with healthy male volunteers [29]. The HPA axis coordinates the stress response, hippocampus, and memory [30]. Alterations of the HPA axis and hippocampus dysfunctions correlate with mental disorders, such as depression [30]. The hippocampus plays a role in spatial learning and memory [8]. There are many modulators of noise-related stress responses: for example, the feeling of control over the stressor affects the hormonal reaction to stress [31]. In addition, it is very probable that sleep disturbance due to noise affects cognitive function. Road traffic noise above $45 \mathrm{~dB}(\mathrm{~A})$ can lead to sleep disturbance, if windows are opened [32]. Sleep duration and quality affect cognitive performance [33].

The limitations of the current study include possible exposure misclassification of traffic noise exposure, since noise exposure was approximated with a model, and no information was available on 
the modifying residential factors, such as ventilation habits. The study sample with available noise values was also quite small, thus diminishing the statistical power to detect associations. In addition, noise annoyance was measured via a rather crude scale. In a sensitivity analysis with another cutpoint we observed different results, thus non-linear relationships of annoyance with cognition are possible. As for the annoyance, a major limitation and possible source of bias is the lack of information on hearing loss, as discussed above. Moreover, due to the small number of participants reporting substantial annoyance, we used a lower cutpoint ("somewhat" in the main analyses and "moderately" in the sensitivity analyses). Such dichotomization sets a lower cutpoint than the one recommended by the International Commission on Biological Effects of Noise, which limits the comparability of our results. Using a conservative cutpoint does not allow us to differentiate between participants with only minor annoyance and those considerably annoyed. However, considering the small sample size of study participants with modeled traffic noise exposure, the selection of a lower cutpoint was necessary to avoid a statistical power problem. As in many longitudinal studies with elderly participants, healthy survivor bias could influence our results.

Our study has a number of strengths. We assessed day- and nighttime noise exposure simultaneously, and, in addition to modeled residential noise levels, were able to investigate the noise annoyance. Other strengths of the study include assessment of both noise and air pollution, and the validated cognition assessment, standardized for age and educational status.

\section{Conclusions}

Our results reflect the complexity of the relationships of residential noise exposure and annoyance with cognitive performance. Residential noise levels were associated with impaired total cognition and the constructional praxis domain, independently of air pollution. Self-reported traffic noise annoyance was associated with better performance in semantic memory and the constructional praxis domain, which might be a spurious finding due to an uncontrolled confounding by hearing loss. The associations of modeled noise levels and self-reported annoyance with cognition were mutually independent.

Supplementary Materials: The following are available online at http://www.mdpi.com/1660-4601/16/10/1790/s1: Table S1. Description of the extended sample $(N=747)$; Table S2: Adjusted associations of residential noise levels and annoyance with dichotomized cognitive scores $(N=288)$. Results are presented as odds ratios with $95 \%$ confidence intervals; Table S3. Adjusted association of LNIGHT $\geq 40 \mathrm{~dB}(\mathrm{~A})$ with dichotomized cognitive scores; Table S4. Adjusted association of noise annoyance with dichotomized cognitive scores in the extended dataset $(N=747)$; Table S5. Adjusted association of annoyance (cutpoint "moderately") with dichotomized cognitive scores; Table S6. Effect modification analysis, using combined residential noise exposure and annoyance at night in the main adjusted model. Odds ratios and 95\% confidence intervals are presented; Table S7. Associations of residential noise with annoyance; Figure S1. Distributions of CERAD-Plus z-scores in main sample $(N=288)$.

Author Contributions: Data curation: H.A. and T.S.; Formal analysis: C.W.; Writing-original draft: K.B.F.; Writing-review and editing: K.B.F., C.W., H.A., and T.S.

Funding: The SALIA follow-up study 2008 was funded by the German Statutory Accident Insurance (DGUV) Grant No: 617.0-FP266.

Acknowledgments: We thank all SALIA study members and staff involved in data collections, and also the respective funding bodies. SALIA study directorate: R. Dolgner, U. Krämer, U. Ranft, T. Schikowski. Scientific Team Baseline: A.W. Schlipköter, M.S. Islam, A. Brockhaus, H. Idel, R. Stiller-Winkler, W. Hadnagy, T. Eikmann. Scientific Team Follow-up: D. Sugiri, A. Hüls, B. Pesch, A. Hartwig, H. Käfferlein, V. Harth, T.Brüning, T. Weiss. Study Nurses: G. Seitner-Sorge, V. Jäger, G. Petczelies, I. Podolski, T. Hering, M.Goseberg. Administrative Team: B. Schulten, S. Stolz. During the last decades many scientists, study nurses, and laboratories were involved in conducting the study. We are most grateful to all the women from the Ruhr area and Borken who participated in the study over the course of decades and the local health departments for organizing the study. We are most indebted to D. Sugiri, who performed modelling of air pollution with the ESCAPE LUR model, and who assigned residential levels of road traffic noise and air pollution to the addresses of the SALIA study participants.

Conflicts of Interest: The authors declare no conflict of interest. 


\section{References}

1. Basner, M.; Babisch, W.; Davis, A.; Brink, M.; Clark, C.; Janssen, S.; Stansfeld, S. Auditory and non-auditory effects of noise on health. Lancet 2014, 383, 1325-1332. [CrossRef]

2. Clark, C.; Paunovic, K. WHO environmental noise guidelines for the european region: A systematic review on environmental noise and cognition. Int. J. Environ. Res. Public Health 2018, 15, 285. [CrossRef]

3. Elmenhorst, E.M.; Elmenhorst, D.; Wenzel, J.; Quehl, J.; Mueller, U.; Maass, H.; Vejvoda, M.; Basner, M. Effects of nocturnal aircraft noise on cognitive performance in the following morning: Dose-response relationships in laboratory and field. Int. Arch. Occup. Environ. Health 2010, 83, 743-751. [CrossRef] [PubMed]

4. Elmenhorst, E.-M.; Quehl, J.; Müller, U.; Basner, M. Nocturnal air, road, and rail traffic noise and daytime cognitive performance and annoyance. J. Acoust. Soc. Am. 2014, 135, 213-222. [CrossRef] [PubMed]

5. Schapkin, S.A.; Falkenstein, M.; Marks, A.; Griefahn, B. Executive brain functions after exposure to nocturnal traffic noise: Effects of task difficulty and sleep quality. Eur. J. Appl. Physiol. 2006, 96, 693-702. [CrossRef] [PubMed]

6. Wright, B.; Peters, E.; Ettinger, U.; Kuipers, E.; Kumari, V. Moderators of noise-induced cognitive change in healthy adults. Noise Health 2016, 18, 117. [CrossRef] [PubMed]

7. European Environmental Agency. Noise in Europe 2014; European Environmental Agency: Copenhagen, Denmark, 2014; ISBN 9789292135058.

8. Tzivian, L.; Dlugaj, M.; Winkler, A.; Hennig, F.; Fuks, K.; Sugiri, D.; Schikowski, T.; Jakobs, H.; Erbel, R.; Jöckel, K.H.; et al. Long-term air pollution and traffic noise exposures and cognitive function: A cross-sectional analysis of the Heinz Nixdorf Recall study. J. Toxicol. Environ. Health—Part A Curr. Issues 2016, 79, 1057-1069. [CrossRef] [PubMed]

9. Gauthier, S.; Reisberg, B.; Zaudig, M.; Petersen, R.C.; Ritchie, K.; Broich, K.; Belleville, S.; Brodaty, H.; Bennett, D.; Chertkow, H.; et al. Mild cognitive impairment. Lancet (Lond. Engl.) 2006, 367, 1262-1270. [CrossRef]

10. Passchier-Vermeer, W.; Passchier, W.F. Noise Exposure and Public Health Noise Exposure and Public Health Characterization of Noise Exposure. Environ. Health 2000, 108, 123-131.

11. Schikowski, T.; Sugiri, D.; Ranft, U.; Gehring, U.; Heinrich, J.; Wichmann, H.-E.; Krämer, U. Long-term air pollution exposure and living close to busy roads are associated with COPD in women. Respir. Res. 2005, 6, 152. [PubMed]

12. Schikowski, T.; Vossoughi, M.; Vierkötter, A.; Schulte, T.; Teichert, T.; Sugiri, D.; Fehsel, K.; Tzivian, L.; Bae, I.S.; Ranft, U.; et al. Association of air pollution with cognitive functions and its modification by APOE gene variants in elderly women. Environ. Res. 2015, 142, 10-16. [CrossRef] [PubMed]

13. Vossoughi, M.; Schikowski, T.; Vierkötter, A.; Sugiri, D.; Hoffmann, B.; Teichert, T.; Herder, C.; Schulte, T.; Luckhaus, C.; Raulf-Heimsoth, M.; et al. Air pollution and subclinical airway inflammation in the SALIA cohort study. Immun. Ageing 2014, 11, 5. [CrossRef] [PubMed]

14. European Commission. Directive 2002/49/EC of the European Parliament and of the Council of 25 June 2002 relating to the assessment and management of environmental noise. Off. J. Eur. Commun. 2002, L189, 2002. Available online: https://publications.europa.eu/s/lKRR (accessed on 20 May 2019).

15. Fields, J.M.; De Jong, R.G.; Gjestland, T.; Flindell, I.H.; Job, R.S.F.; Kurra, S.; Lercher, P.; Vallet, M.; Yano, T.; Guski, R.; et al. Standardized general-purpose noise reaction questions for community noise surveys: Research and a recommendation. J. Sound Vib. 2001, 242, 641-679. [CrossRef]

16. Ranft, U.; Schikowski, T.; Sugiri, D.; Krutmann, J.; Krämer, U. Long-term exposure to traffic-related particulate matter impairs cognitive function in the elderly. Environ. Res. 2009, 109, 1004-1011. [CrossRef]

17. Mirza, S.S.; Ikram, M.A.; Bos, D.; Mihaescu, R.; Hofman, A.; Tiemeier, H. Mild cognitive impairment and risk of depression and anxiety: A population-based study. Alzheimer Dement. 2017, 13, 130-139. [CrossRef]

18. ESCAPE Project. Exposure assessment manual. 2010. Available online: http://escapeproject.eu/manuals/ ESCAPE_Exposure-manualv9.pdf (accessed on 20 May 2019).

19. R Core Team. R: A Language and Environment for Statistical Computing; R Foundation for Statistical Computing: Vienna, Austria, 2018; Available online: http://www.R-project.org/ (accessed on 6 June 2018).

20. Dridan, B.A.; Ong, B.; Lloyd, S.; Evans, L.; Crowe, S.F. The Simple Copy Task: Detecting Higher Order Visual Processing Deficits in Schizophrenia, Dementia, and Movement Disorder Groups. Aust. Psychol. 2013, 48, 98-109. [CrossRef] 
21. Fillenbaum, G.G.; Burchett, B.M.; Unverzagt, F.W.; Rexroth, D.F.; Welsh-Bohmer, K. Norms for CERAD Constructional Praxis Recall. Clin. Neuropsychol. 2011, 25, 1345-1358. [CrossRef]

22. Van Kempen, E.; van Kamp, I.; Nilsson, M.; Lammers, J.; Emmen, H.; Clark, C.; Stansfeld, S. The role of annoyance in the relation between transportation noise and children's health and cognition. J. Acoust. Soc. Am. 2010, 128, 2817-2828. [CrossRef]

23. Roberts, K.L.; Allen, H.A. Perception and cognition in the ageing brain: A brief review of the short- and long-term links between perceptual and cognitive decline. Front. Aging Neurosci. 2016, 8, 1-7. [CrossRef]

24. Sandrock, S.; Schütte, M.; Griefahn, B. Mental strain and annoyance during cognitive performance in different traffic noise conditions. Ergonomics 2010, 53, 962-971. [CrossRef]

25. Babisch, W.; Swart, W.; Houthuijs, D.; Selander, J.; Bluhm, G.; Pershagen, G.; Dimakopoulou, K.; Haralabidis, A.S.; Katsouyanni, K.; Davou, E.; et al. Exposure modifiers of the relationships of transportation noise with high blood pressure and noise annoyance. J. Acoust. Soc. Am. 2012, 132, 3788-3808. [CrossRef] [PubMed]

26. Chiovenda, P.; Pasqualetti, P.; Zappasodi, F.; Ercolani, M.; Milazzo, D.; Tomei, G.; Capozzella, A.; Tomei, F.; Rossini, P.M.; Tecchio, F. Environmental noise-exposed workers: Event-related potentials, neuropsychological and mood assessment. Int. J. Psychophysiol. 2007, 65, 228-237. [CrossRef]

27. Sinanaj, I.; Montandon, M.L.; Rodriguez, C.; Herrmann, F.; Santini, F.; Haller, S.; Giannakopoulos, P. Neural underpinnings of background acoustic noise in normal aging and mild cognitive impairment. Neuroscience 2015, 310, 410-421. [CrossRef]

28. Jafari, Z.; Kolb, B.E.; Mohajerani, M.H. Chronic traffic noise stress accelerates brain impairment and cognitive decline in mice. Exp. Neurol. 2018, 308, 1-12. [CrossRef] [PubMed]

29. Pouryaghoub, G.; Mehrdad, R.; Valipouri, A. Effect of acute noise exposure on salivary cortisol: A randomized controlled trial. Acta Med. Iran. 2016, 54, 658-662.

30. Wingenfeld, K.; Wolf, O.T. Stress, Memory, and the Hippocampus. In The Hippocampus in Clinical Neuroscience; Szabo, K., Hennerici, M.G., Eds.; Karger Publishers: Basel, Switzerland, 2014; Volume 34, pp. 109-120.

31. Arnsten, A.F.T. Stress signalling pathways that impair prefrontal cortex structure and function. Nat. Rev. Neurosci. 2009, 10, 410-422. [CrossRef]

32. Berglund, B.; Lindvall, T.; Schwela, D.H. New WHO guidelines for community noise. Noise Vib. Worldw. 2000, 31, 24-29. [CrossRef]

33. Gildner, T.E.; Liebert, M.A.; Kowal, P.; Chatterji, S.; Snodgrass, J.J. Associations between Sleep Duration, Sleep Quality, and Cognitive Test Performance among Older Adults from Six Middle Income Countries: Results from the Study on Global Ageing and Adult Health (SAGE). J. Clin. Sleep Med. 2014, 10, 613-621. [CrossRef] [PubMed]

(C) 2019 by the authors. Licensee MDPI, Basel, Switzerland. This article is an open access article distributed under the terms and conditions of the Creative Commons Attribution (CC BY) license (http://creativecommons.org/licenses/by/4.0/). 